\title{
Izquierdas y cultura militante en el frente minero: Perú 1928-1930*
}

\section{Lefts and militant culture in the mining field: Peru 1928-1930}

\author{
Ricardo Melgar Bao \\ Instituto Nacional de Antropología e Historia \\ melgarr@gmail.com
}

(México)

Recibido: 29-04-2019

Aceptado: 29-10-2019

Publicado: 05-06-2020

\section{Resumen}

La militancia como correa de transmisión bidireccional entre Partido-sindicato-bases mineras de la Sierra Central del Perú, posibilitó la elaboración de una estrategia de cooptación revolucionaria, solventada por su estrategia espacial, sus redes, formas orgánicas, tradiciones de resistencia minera y tácticas inéditas de lucha. Presentamos cómo la corriente socialista y el sindicalismo clasista arraigaron en dicho proletariado, bajo la conducción de José Carlos Mariátegui.

Palabras Clave: espacio regional, proletariado mixto, mineros, redes, sindicalismo clasista, sindicalismo rojo, socialismo, comunismo.

*. Agradezco a la historiadora y latinoamericanista Perla Jaimes Navarro por su atenta lectura y su colaboración en la consulta de fuentes primarias. 


\begin{abstract}
Militancy as a bidirectional transmission belt between the Party-union-mining bases of the central highlands of Peru, enabled the elaboration of a strategy of revolutionary cooptation, solved by its space strategy, its networks, organic forms, traditions of mining resistance and unprecedented tactics of struggle. We present how the socialist current and the class syndicalism rooted in this proletariat, under the leadership of José Carlos Mariátegui.
\end{abstract}

Keywords: regional space, mixed proletariat, miners, networks, class syndicalism, red syndicalism, socialism, communism.

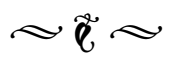

\section{Introducción}

La historiografía del movimiento minero padeció un desplome generalizado, marcado en parte por la Guerra Interna y la censura (1985-2000), de la que se derivó la destrucción de fuentes, la estigmatización y la criminalización de la investigación. Se salvó parcialmente el Archivo Mariátegui y la colección de documentos impresos de Ricardo Martínez de la Torre. Los más recientes estudios mineros privilegian el periodo colonial, las primeras décadas de la República o las tres últimas del presente. Por lo anterior, reabrimos la cuestión de la recepción política y sindical en los Andes centrales, abordada en dos libros que son considerados fundantes: Historia del movimiento obrero minero metalúrgico, de Denis Sulmont (1980) y Los mineros de la Cerro de Pasco, 1900-1930, de Alberto Flores Galindo (1983). Deudores del criterio clasista de análisis, los autores obvian la heterogeneidad de las adscripciones étnicas originarias y la mayoritaria pertenencia huanca del proletariado minero. Reconocen los contactos de Mariátegui con dirigentes mineros y algunos de sus escritos, no su proyecto estratégico socialista. Este úl- timo solo cobrará visibilidad recuperando la espacialidad local-regional-nacional, signada por un "momento constitutivo" y otros sucesos complementarios. Su contenido se sustenta en la presencia avasalladora de la Cerro de Pasco Corporation en la Sierra Central a partir de 1902: acumulación originaria, despojo de tierras comunales, atracción de la fuerza de trabajo huanca, desarrollo ferroviario, depredación ambiental de la fundición (1922-1928), integración al mercado mundial y desarrollo de las formas de resistencia rural-urbana, potenciadas por la recepción libertaria, sindicalista revolucionaria y socialista. El "momento constitutivo" no desterró en el imaginario huanca y criollo-mestizo, los sedimentos mitológicos del "momento constitutivo arcano": el "comunismo agrario" o "socialismo indígena" (Zavaleta, 2009). Proponemos una relectura y reinterpretación de las fuentes, agregando dos entrevistas a protagonistas de época: Joel Marroquín y Esteban Pavletich.

En lo que respecta a la literatura cominternista acerca de América Latina, no existen a la fecha estudios que aporten nuevos elementos al esclarecimiento de la diferenciación entre 
el sindicalismo clasista y el rojo, ni a la añeja caracterización de Melgar (1988). La gran ausencia son las referencias al sindicalismo minero durante la hegemonía bujarinista. En general, la literatura cominternista contemporánea sobre la Internacional Sindical Roja (en adelante, ISR) reproduce un paradigma interpretativo eurocéntrico.

El proletariado minero regional tuvo cuatro particularidades: era mayoritariamente huanca y estacional (estiaje), procedían de las comunidades campesinas, estaban al servicio de la empresa minero-metalúrgica estadounidense Cerro de Pasco Corporation, aprovechando la red ferroviaria. Tales condiciones: ¿ampliaron la lucha y politización minero-campesina? El corredor ferroviario, el servicio postal, cablegráfico y de publicaciones periódicas (Amauta y Labor), ¿facilitó el proceso de recepción del socialismo y del sindicalismo clasista, auspiciado por Mariátegui? Las redes cultivadas por los socialistas, ¿le permitieron a Mariátegui diseñar una concepción y plan estratégico?

Sostenemos que Mariátegui, gracias a sus redes minero-ferroviarias-campesinas, orientó la renovación de las prácticas de solidaridad, resistencia y combate, desde privilegiados espacios de articulación: Morococha, Jauja, $\mathrm{Mu}-$ quiyauyo y La Oroya. La articulación y configuración del espacio regional se dio por la conjunción dominante minero-metalúrgico y al tejido ferroviario. Las estaciones del Ferrocarril Central vinculadas regionalmente fueron: Callao (1851), Chosica (1870), La Oroya (1893), Morococha (1903 y 1921), Cerro de Pasco (1904), Jauja (1908), Lima (Desamparados, 1912) y Vitarte (¿1918?). El desarrollo del sindicalismo ferroviario tuvo como eje principal la estación de Chosica (Portocarrero, 1987, p. 194), articulándose gradualmente con las organizaciones mineras y campesinas de la región. Esteban Pavletich evocó que el trabajo de masas en la región central no fue espontáneo:

con motivo de acrecentar desde el punto de vista de fuerzas fundamentales de la industria peruana que realmente representaban la economía básica del país, como eran mineros, petroleros, ferroviarios, etc., bajo la dirección de Mariátegui, se destacó al centro de la República a varios delegados del Partido Comunista ya en gestación (Melgar Bao, 1974, p. 22).

Consideramos oportuno diferenciar el "espacio público social" del estratégico. El primero, signa el corredor de ideas suprarregional, documentado por la circulación de militantes y periódicos como El Trabajador Latinoamericano (1928), vocero de la ISR, la cual transitó del sindicalismo clasista al rojo en el breve lapso de 1929 a 1934 (Melgar Bao, 1988 y 2016) y su réplica nacional El Trabajador (1930-1931), vocero de la Confederación General de Trabajadores del Perú (en adelante, CGTP) (Sánchez Ortiz, 1987, p. 29). En cambio, el "espacio estratégico" fue política y culturalmente generado desde un centro hacia su hinterland con un propósito revolucionario. Mariátegui, desde Lima, configuró un espacio estratégico socialista capitalizando las organizaciones y tradiciones de las clases y minorías étnicas subalternas. Lefebvre sostiene que el "espacio estratégico", siendo generado y condicionado por los factores económicos y técnicos, es presidido por su función y orientación política y que es estratégico porque utiliza tácticas de confrontación, persuasión, acumulación y uso

1. “...el espacio público no es sólo el lugar de la comunicación de cada sociedad consigo misma sino también, y quizás, ante todo, el lugar de una comunicación de las sociedades distintas entre sî" (Ferry, 1992, p. 20). 
de recursos materiales en sus acciones con un fin revolucionario. Emplea "recursos propios de los espacios periféricos” y la riqueza -teórica e ideológica- procedente de un centro industrial urbanizado (2013, p. 140).

Se vivía un proceso transicional. Es decir, un proceso de acoplamiento entre las tradicionales formas de Resistencia y nuevas modalidades socialistas y sindicales de organización, comunicación y lucha. Afirmamos que, entre 1927 y 1930, emergió una nueva cultura y orientación sindical minero-metalúrgica recuperando, pragmáticamente, el tejido práctico y relacional de las corrientes mutualistas, anarcosindicalistas y sindicalistas revolucionarias.

\section{El imperialismo y la cuestión minera}

A partir de 1902, la Cerro de Pasco Invesment Company impulsó la explotación de los yacimientos mineros de la Sierra Central. Sus accionistas, entre 1902 y 1914, impulsaron la formación de diversas compañías mineras, propias o mixtas, para extender sus operaciones a los más importantes. Entre esas empresas, destacó la Morococha Mining Company que, al igual que sus símiles, en 1915 se integró a una nueva razón social, la Cerro de Pasco Copper Corporation, que se acondicionaba mejor al perfil monopolista que venía adquiriendo. Las inversiones yanquis, en 1929, ascendieron a un total de 124 millones de dólares invertidos por sus empresas, de los cuales correspondieron a la minería 79 millones 490 mil dólares (Barce1li, 1971, p. 201).

El volumen de la fuerza laboral creció de 22.000 obreros en 1919 (Flores Galindo, 1974, p. 42), a 32.047 en 1929 , lo que equivale a un incremento de 45,66\%. El mismo año, en las minas de la Cerro de Pasco laboraban 7.500 mineros, un $34,09 \%$ del sector minería y petróleo. Una década más tarde, dicha empresa contaba con 12.858 trabajadores, un 40,12\% del universo laboral. El incremento de la fuerza de trabajo en las minas, entre 1919 y 1929 , alcanzó un índice del 41,67\% (Barcelli, p. 201). La empresa no dudó en aplicar la táctica del lock out en tiempos de crisis de los precios en el mercado mundial en 1919 y 1930.

La vida de los mineros transcurría entre la mina y el campamento. El relevo generacional se expresó en una mayoría adolescente, entre los doce y quince años de edad, con más escolaridad. En Morococha, entre 1920 y 1928, el índice de instrucción básica fluctuó entre el $52 \%$ y el $81 \%$ e incidió en un mayor interés por las lecturas proletarias. Los mineros promovieron la creación de escuelas (Barcelli, p. 201). Por su lado, los profesores jóvenes- con sensibilidad de cambio- se agruparon y constituyeron en 1928 la Asociación Provincial de Maestros de Jauja, adscrita a la Internacional de Trabajadores de la Enseñanza y liderada por Teófilo Aguilar. ${ }^{2}$

La distribución espacial y las construcciones mineras expresaban la polaridad de intereses sociales. Las viviendas de ingenieros y empleados eran de calidad y amplitud. Contaban con servicios: club, hotel, tienda, clínica y transporte. Por su lado, los mineros alquilaban viviendas precarias y estrechas de 2 por 2,50 metros. Excepcionales fueron las de 4 por 4 . Operaba "La Mercantil", tienda de raya que surtía víveres, implementos de trabajo y efectos

2. (abril de 1930). Amauta 30, p. 89. Archivo Personal del Autor. 
personales aplicando descuentos al salario. $\mathrm{Su}$ esparcimiento era en las cantinas y, en menor medida, en actividades deportivas y culturales. Se constituyeron nuevos espacios de sociabilidad, educación e interacción gremial. Su contacto con el exterior fue a través de ferroviarios y pasajeros: paisanos, comerciantes minoristas, familiares y amigos.

La contaminación generada por los humos de la fundición suscitó gran mortandad de ganado, afectación de aguas, sembradíos, pastizales y la salud. La ruina económica y la indefensión legal suscitaron un proceso de concentración de la tierra en manos de la Cerro de Pasco, convirtiéndose en el más grande poseedor de minas y tierras (Kapsoli, 1980).

Por lo anterior, los mineros y comuneros huancas convirtieron a la empresa yanqui en su principal fuente de empleo y antagonismo: para 1924 la empresa poseía 320.000 has de tierra y en 1925 compró la Sociedad Ganadera de Junín (Kapsoli, 1972). De los seis campamentos mineros- La Oroya, Cerro de Pasco, Casapalca, Goyllarizquizga, Yauricocha y Morococha-, era este último el que se destacaba por su tradición de lucha y su mayor concentración laboral en 1926: 3.146 mineros.

La precarización laboral y ambiental (aniegos del socavón en Morococha y los humos de la fundición de la Oroya) facilitó el trabajo sindical y socialista. A la jornada de nueve a doce horas, según las "tareas asignadas", se sumaban las faenas extraordinarias. Los turnos de trabajo eran dos: de 7:00 am a 4:00 pm y de 4:00 pm a 7:00 am. Jorge del Prado, comunista destacado en las minas, trabajó como obrero "pallaquero" por recomendación del Comité Central de Reclamos de Morococha. Cubría el turno nocturno. Su labor "consistía en limpiar el mi- neral separándolo de la tierra y escorias al salir de las minas", mientras realizaba su trabajo político-sindical (Del Prado, 2010, pp. 42-43).

El proletariado minero no era, en sentido estricto, moderno. Tenía rasgos de éste, como el salario, subordinado a formas semiserviles (enganche, tambos o tiendas de raya y coerciones político-sociales). Este sector, en la medida que procedía en su mayor parte de las comunidades andinas sin perder sus vínculos, ha sido caracterizado como "proletariado mixto", "semiproletariado" o "jornaleros estacionales". Lo anterior explica que buena parte de las amonestaciones patronales a los mineros fuese por ausencia injustificada. Solían faltar para ir a sus pueblos, por motivos familiares, agrícolas o festivos (Kruijt y Vellinga, 1980, p. 1505). Muchos de ellos, los fines de semana atendían faenas agrícolas en sus comunidades (Mejía, 1971, p. 5).

En ese contexto, no tardaron en manifestarse las primeras formas de resistencia del proletariado minero contra el orden opresivo, los salarios deprimidos y la prolongada jornada laboral. Los mineros comenzaron a expresarse de manera espontánea a través de su ausencia temporal o deserción, del motín, la revuelta y el ataque a las instalaciones de la empresa. ${ }^{3}$ Bajo las orientaciones del mutualismo, anarcosindicalismo y sindicalismo revolucionario, se gestaron nuevas formas de organización, así como prácticas solidarias y de lucha contra el sistema de enganche, el régimen salarial, la tienda de raya y las condiciones de trabajo.

3. De acuerdo a un informe de Pedro Zulen (1910), las casas enganchadoras reportaron un significativo incremento en el número de fugados y morosos: la Casa Castro, 2.369; la Casa Aizcorbe, 2.114, y la Casa Grelland, 420, entre las que suman un total de 4.903 (Flores Galindo, 1974, p. 68). 
Antecedentes notables nos remiten a junio de 1917, cuando los mineros de Smelter y Cerro lograron la primera victoria laboral frente a la Cerro de Pasco (Barcelli, 1971, pp. 113-117). Desde 1918 existían nexos entre la Central Obrera de Mineros del Centro y la Federación Obrera Local, de filiación anarcosindicalista (Sulmont, 1980, p. 14). Dicha Central logró sentar sus bases en dos campamentos mineros. Fue su sección de Morococha la que inició la huelga del 7 de enero de 1919 (Barrientos, 1958, p. 153), tras presentar su demanda de incremento salarial del 50\%. El paro fue garantizado por piquetes mineros de vigilancia. La patronal osciló entre conceder un 20\% de aumento o recurrir al lock out. El 13 de enero devino en amotinamiento, tomando los contornos de una revuelta expandida con prácticas de sabotaje (inundación de las lumbreras de Natividad, San Francisco y Desaguadora), asedio, apedreo e intento de dinamitar la residencia del staff de la Empresa en Tucto. Resultaron cruentamente reprimidos (Flores Galindo, 1974, pp. 90-91). La táctica del sabotaje libertario fue la que precipitó el desenlace. Vino la intervención policial y el lock out, aprovechando la caída internacional de los precios del cobre y el trabajo estacional minero. El ejército sometió a los paristas y los subió a 18 vagones de tren para trasladarlos a estaciones próximas a sus localidades de origen (Flores Galindo, pp. 91-92). En cambio, en Casapalca, la protesta del proletariado se libró contra el monopolio de venta y alza de precios de la tienda de raya, desembocando en un devastador atentado dinamitero.

En resumen, son atribuibles a las corrientes libertarias: las sociedades de resistencia (Estrella de los Andes, Central Obrera de Mineros del Centro), el boicot, el sabotaje, el periódico de agitación (El Correo de Morococha) y la huelga de 1919. Espontaneidad, debilidad sindical y violencia, se aproximaron a lo que se denomina "sindicalismo de revuelta" (Pécaut, 1973; Vitale, 1986). Lecciones de esta lucha fueron tomadas en cuenta por el sindicalismo clasista minero en los años '20. Cesáreo Marroquín Fernández, dirigente de la jornada huelguística de 1919, escapó de la represión refugiándose en Vitarte, gracias a la hospitalidad clasista y solidaria de Julio Portocarrero y de Laguado, a los que transmitió las experiencias de lucha. ${ }^{4}$

En 1920, la represión afectó severamente la resistencia proletaria en los asientos mineros. Al decir de Mariátegui: "todo obrero acusado de intento de organización de los trabajadores, aunque sólo sea con fines culturales o mutuales, es inmediatamente despedido por la empresa" (1987, p. 36). Frente a la política represiva, las diversas corrientes y organizaciones obreras se solidarizaron entre sí. Síntomas de su recuperación y renovación clasista aparecieron a partir de 1927.

Gracias a la circulación de Amauta (19261930) y Labor (1928-1929), las ideas socialistas y el sindicalismo clasista fueron echando raíces. Se vendían en la librería de Carlo Pezzutti, en Morococha y eran distribuidas a lectores de Jauja, La Oroya, Cerro de Pasco y Huancayo (Mazzi, 2017, p. 92), atrayendo a mineros, profesores y cuadros libertarios. Máximo Pecho, en Jauja, publicaba propaganda anarquista y socialista y fue agente distribuidor de Amauta y Labor. ${ }^{5}$ Se vivía el tránsito de los periódicos li-

4. Entrevista a Joel Marroquín Osorio, realizada por Ricardo Melgar Bao, 7 de abril de 1987.

5. Lista de Agentes de la Editorial Minerva. PE PEAJCM EEM-F-02-02-01-02-003. Archivo José Carlos Mariátegui. Recuperado de http://archivo. mariategui.org/index.php/lista-de-agentes-de-laeditorial-minerva 
bertarios: El Correo de Morococha (1915-1918), de Marroquín y Via Libre (1919-1923) de Pecho, a los de orientación socialista: El Martillo (1928) y Alborada (1929), de Gamaniel Blanco y César Augusto Palacios (Mazzi, p. 98) y los propiamente comunistas: Andes, El Minero, El Trabajador Latinoamericano y La Correspondencia Sudamericana. En general, los periódicos enriquecieron los debates proletarios, sus formas de organización, sus redes y su praxis.

\section{Hacia el sindicalismo clasista}

Recordemos que, en el seno de la ISR, durante los años 1920 y 1927 se generó y afirmó el "sindicalismo clasista", adherido al principio de la lucha de clases, la solidaridad proletaria y campesina, el frente único, la central nacional e internacional. Su heterogeneidad orgánica y táctica no pudo ser centralizada por los dirigentes soviéticos: Solomón Lozovski y Mijaíl Tomskibajo la égida bujarinista (Lozovski, 1930b). Gracias a ello, Mariátegui se afirmó como su heterodoxo introductor. Sostuvo que:

El frente único no anula la personalidad, no anula la filiación de ninguno de los que lo componen. No significa la confusión ni la amalgama de todas las doctrinas en una doctrina única. Es una acción contingente, concreta, práctica. El problema del frente único considera exclusivamente la realidad inmediata, fuera de toda abstracción de toda utopía. Preconizar el frente único no es, pues, preconizar el confusionismo ideológico. Dentro del frente único cada cual debe conservar su propia filiación y su propio ideario. Cada cual debe trabajar por su propio credo. Pero todos deben sentirse unidos por la solidaridad de clase, vinculados por la lucha común, ligados por la misma voluntad revolucionaria y la misma pasión reno- vadora. Formar un frente único es tener una acción solidaria ante un problema concreto, ante una necesidad urgente (1987, p. 107). ${ }^{6}$

El sindicalismo clasista asimiló y reconfiguró las formas de organización previas, como la Sociedad Pro-Cultura Popular y el Club Movilizables núm. 1 de Morococha. De su seno emergieron los comités de organización sindical y el Comité Central de Reclamos, liderados por Gamaniel Blanco, Alejandro Loli, Manuel Vento, Ramón Azcurra y Adrián Sovero (Del Prado, 2010, p. 30). Mantuvieron con Mariátegui relaciones epistolares y un significativo encuentro en Lima en octubre de 1929. ${ }^{7} \mathrm{Di}$ chos vínculos se fortalecieron con el traslado de cuadros socialistas a las regiones mineras: el médico Hugo Pesce al hospital de Chulec (La Oroya) y Jorge del Prado a Morococha, entre otros. Nicolás Terreros, originario de la comunidad huanca de Muquiyauyo, cumplió una función de enlace rural-minero cuando trabajó como carpintero en la fundición de $\mathrm{La}$ Oroya. Se había vinculado a Mariátegui a fines de 1923, en la Universidad Popular González Prada (Portocarrero, 1987, pp. 145-155).

La espacialización de las redes militantes se tejió desde el núcleo socialista limeño, considerando sus tradiciones de resistencia y tipos de asentamiento (campamento minero, fundición, ciudad y comunidad). Mariátegui afirmó que tanto La Oroya (km 183) como Moroco-

6. Véase: $\mathrm{E} 11^{\circ}$ de Mayo y el frente único (1 de mayo de 1924). El Obrero Textil, año 5, 59. Biblioteca Nacional del Perú, Lima.

7. José Carlos Mariátegui junto a los dirigentes de la Federación de Trabajadores Mineros de Morococha (II) [foto]. PE_PEAJCM_JCM-F-03-04-4.1-4.1.5-034, 1929 Archivo José Carlos Mariátegui. Recuperado de http://archivo.mariategui.org/index.php/jose-carlosmariategui-junto-a-los-dirigentes-de-la-federacion-detrabajadores-mineros-de-morococha-ii 
cha (km 147) constituían "puntos donde ventajosamente puede operar la propaganda clasista” (1987, p. 45). En lo que respecta a $\mathrm{Mu}-$ quiyauyo y Jauja, retomó la caracterización que hizo el socialista Hildebrando Castro Pozo en 1924, por la conjunción y complementariedad entre la tradición comunal indígena y la operación de su planta eléctrica a favor de la ciudad de Jauja y varios asientos mineros y distritos rurales (Mariátegui, 1957, p. 72). Hacia 1928 encontramos rasgos de una vanguardia minera etnoclasista que tuvo como eje central el campamento de Morococha. Liquidada la dirección sindicalista revolucionaria con el lock out de 1919, sólo existía el Club Movilizables núm. 1 de Auxilios Mutuos.

Los socialistas de Morococha y los de la ciudad-mercado de Jauja, coadyuvaron a la articulación del proyecto de Mariátegui. Su convergencia aproximó a los comuneros y mineros solidariamente en acciones reivindicativas y revolucionarias. El autor de Siete ensayos... consideraba que, más allá del proceso de diferenciación social intracomunitario, persistía culturalmente su "espíritu comunista", convergiendo con el ideal justiciero del proletariado, encarnado regionalmente en los mineros. Creía que el "socialismo indígena" encontraría "el medio de rehacerla, mantenerla o subrogarla [a la comunidad]" (Mariátegui, 1957, p. 71), soporte de la vía andina modernizante y revolucionaria al socialismo.

Supo vertebrar a los sectores populares y sus vanguardias de Lima-Callao, con los ferroviarios, mineros y campesinos de la Sierra Central, nervio y motor de lo que Mariátegui llamó "el Perú profundo". Proyecto a largo plazo que se fue extendiendo en abanico desde los centros de concentración y actividad proletaria, ubicados principalmente en la costa hacia la sierra, desde las ciudades costeñas a las minas y comunidades andinas. Su concepción, plan, forma y estilo de trabajo de masas atendió las particularidades etnoclasistas, tradiciones de resistencia, volumen y ubicación estratégica. Jauja y Morococha fueron los pivotes de su estrategia regional. En Jauja se consolidó el trabajo partidario y sindical en el seno de las comunidades campesinas, el magisterio primario y rural, irradiando en el artesanado de los poblados y ciudades menores. En su núcleo politico militaban Moisés Arroyo Posadas, Nicolás Terreros, Abelardo Solís, Pedro Monge, Teófilo Aguilar Peralta, Alberto Espinoza Bravo y el comunero Delgado. Su mérito político se expresó en haberse convertido en un polo de concentración ideológica y acción política, atrayendo a libertarios y radicales. Impulsaron, a partir del Círculo Obrero y su Centro Artístico y Cultural, la difusión del marxismo y de la experiencia revolucionaria de la Rusia soviética. Lograron la difusión y organización de bibliotecas en las comunidades y en los poblados y campamentos mineros. Organizaron la Federación de Trabajadores del Centro, a partir de la Federación de Trabajadores de la Provincia de Jauja, la cual pretendía aglutinar a los indígenas, campesinos y mineros como sus eslabones centrales (Arroyo Posadas, 1980, pp. 61-74).

Del núcleo político de Jauja fueron responsables del trabajo en el frente minero, Solís y Arroyo Posadas. Con la anuencia de Mariátegui, centraron su atención en el campamento minero de Morococha considerando que sus trabajadores procedían de las comunidades campesinas de la región. Poco importaba que la formal división jurídica y político-territorial del Estado tuviese a Morococha y a Jauja desvinculados y adscritos a dos provincias distintas. Su regionalización político-cultural 
se ajustó a los nexos reales que ligaban a estas localidades. Revisada la procedencia de la fuerza de trabajo existente en Morococha en 1924, notanmos un 49\% de migrantes jaujinos (Flores Galindo, 1974, p. 24).

La afluencia de fuerza de trabajo a las minas, particularmente a Morococha, se explica por el hecho de que las casas enganchadoras de Arístides Castro, Pedro Aizcorbe y los hermanos Grelland operaban desde Jauja, con la finalidad de abastecer de fuerza de trabajo semiservil las haciendas ganaderas alteñas y los campamentos mineros. Se aprovecharon de la indefensión política de los comuneros, de su proceso de diferenciación social, agravado por la acción voraz de la Cerro de Pasco sobre las tierras comunales arruinadas por la contaminación de la fundición de La Oroya. La compleja y conflictiva situación se explica, además, por la consistencia de los lazos que unían a campesinos y mineros. Agregamos un elemento que coadyuvó a favor de la transferencia y movilidad coactiva de la fuerza de trabajo, gracias a la expansión del servicio ferroviario (Flores Galindo, p. 43). No fue casual que las redes militantes mineras crecieran por mediación de la Federación de Trabajadores Ferroviarios, liderada por el socialista Avelino $\mathrm{Na}-$ varro (Lévano, 2016). En la misma dirección los mineros tejieron vínculos significativos con trabajadores afincados en Jauja, Chosica, Vitarte y El Callao. La relación con Vitarte fue importante. Estuvo mediada por Julio Portocarrero, dirigente obrero socialista y secretario general de la CGTP, en cuyo proceso de constitución (1929) participaron activamente los trabajadores ferroviarios.

El debate acerca del real drama minero y su futuro continuó su curso. Mariátegui centró su análisis, denuncia y propaganda sobre los luctuosos sucesos del 5 de diciembre de 1928 en Morococha. Un accidente en la mina "Yankee", debido a la imprevisión y negligencia de la empresa, provocó la inundación y derrumbe de una parte de la mina sepultando en vida a 26 mineros y dos empleados estadounidenses. Polarizó la situación el intento de la Cerro de Pasco de eximirse de su responsabilidadfrente a los deudos y, peor aún, de desobligarse frente a las necesarias medidas de seguridad para la protección de los mineros que continuarían operando en los socavones.

A través de las páginas de Amauta y Labor, Mariátegui acicateó el desarrollo del movimiento popular nacional en gestación, superando los límites de la denuncia fácil, episódica $\mathrm{y}$ adjetiva, en favor de su proyecto revolucionario por el control de todos y cada uno de los pivotes de la economía peruana enfeudados a los intereses oligárquicos e imperialistas. La cuestión minera y sindical en otros países aparecía en los diarios nacionales y constituían espejos desde dónde mirarse: la huelga en las minas de carbón en Inglaterra, librada del 3 al 12 de mayo de 1926, atrajo atención y solidaridad internacional. Haya de la Torre remitió el siguiente telegrama: "Trabajadores Manuales Intelectuales América invoca efectiva solidaridad nuestros pueblos con proletariado británico (sic)". ${ }^{8}$

Puntos de engarce de la problemática minera de otros países fueron atendidos por Mariátegui por incidir en el curso del debate peruano. No por casualidad, en febrero de 1927, polemizó con las tesis de César Falcón acerca del conflicto minero que asolaba a Inglaterra.

8. Inserto en carta dirigida a Carlos Quijano. Londres, 10 de mayo de 1926 (Melgar Bao y Montanaro, 2010). 
Falcón (1927) sostenía una postura opuesta a los mineros del carbón de ese país por demandar la nacionalización de las minas en el nombre del socialismo, en lugar de sostenerla en nombre del interés concreto de la economía británica. Tuvo resonancia tanto en las filas del sindicalismo minero como en las del socialismo y aprismo peruanos, enfrascados ya en una importante polémica sobre estatización-nacionalización y capitalismo versus socialismo. Al impugnar las tesis de Falcón, a por obviar el carácter de clase del Estado, criticaba también el reformismo estatalista y aprista emergente.

Mariátegui sostuvo que el accidente de Morococha debía ser motivo de debate sobre la contradicción entre los intereses populares y nacionales y aquellos que representaban al imperialismo, a los terratenientes y a la burguesía intermediaria. A ello dedicó el editorial del núm. 4 de Labor, del 29 de diciembre de 1928. En el mismo número reprodujo la carta de un minero de Morococha y otras informaciones remitidas por la célula de Jauja. Se inició así el proceso político a la penetración imperialista en su expresión particular, las minas. En un artículo publicado en Amauta en el mismo mes, Mariátegui afirmó de manera concluyente:

El capital extranjero que explota las riquezas mineras del país, paga al Perú en salarios y tributos una suma muy modesta, en proporción a sus utilidades. El asunto de los humos de la Oroya es un dato cercano del caso que hace la Cerro de Pasco Copper Corporation de los intereses de las poblaciones, en medio de las cuales se instala. Antes, la Asociación Pro Indígena había tenido ya constante motivo de intervención en el tratamiento y "enganche" de los obreros de las minas. Frente a toda prepotencia de esta empresa, habituada a tratar con insolente desprecio los derechos de sus trabajadores indígenas, debe mantenerse vigilante y solidaria la clase trabajadora. Amauta es su tribuna doctrinaria, pronta siempre a la acusación, alerta siempre a la defensa (Mariátegui, 1928, p. 94).

Mariátegui impulsó la reflexión socialista y el debate político a través de Labor y Amauta. A principios de 1929, en su revista, publicó un artículo de Tristán Marof acerca de la nacionalización de las minas en Bolivia en el cual, con algunos matices y diferencias, hacía forzosa la analogía con el caso peruano. La tesis central aludía a los nexos financieros entre el gobierno de su país y el imperialismo yanqui. Justamente por esos días el régimen de Leguía afrontaba problemas en la consecución de nuevos préstamos con la banca norteamericana, lo cual a su vez comprometía de parte a parte su política frente a las empresas norteamericanas que explotaban las minas de este país. En síntesis, el planteamiento de Marof era el siguiente:

La nacionalización de las minas tiene que ser un fenómeno revolucionario que fatalmente tiene que presentarse en Bolivia. El gobierno actual o todos los gobiernos, no podrán jamás curar la crisis eterna sino a base de empréstitos; no podrán ni velar sus gastos sino a base de empréstitos; no podrán dar un paso sino empujados por los mismos empréstitos. Llegará un día que la capacidad financiera de Bolivia no pueda resistir sus deudas; entonces aparecerá la intervención del acreedor y al aparecer la intervención aparecerá también la Revolución. Siles, el gobernante actual, representa su aliado inconsciente (Marof, 1929, pp. 92-93).

Es seguro que Mariátegui no compartiría en todas sus partes las afirmaciones del socialista boliviano, pero le bastaba que éste aportase elementos para el debate y la convergencia en el marco de una política de frente único revolu- 
cionario. En ese sentido, es que hay que ubicar su flexibilidad en la conducción de Amauta y Labor y no como producto de sus vacilaciones o centrismo pequeñoburgués, atribuidas por los apristas y el Buró Sudamericano de la IC.

Mariátegui no se quedó únicamente en el terreno de la búsqueda y construcción de una reivindicación programática del proletariado y pueblo peruano en su conjunto, él sabía atender al mismo tiempo las exigencias concretas que se derivaron de la catástrofe de Morococha, lo cual le llevó a sostener de manera clara y contundente desde las páginas de Amauta la siguiente declaración:

Tenemos la obligación de hacer llegar a la población obrera de Morococha la expresión de la solidaridad de los grupos de trabajadores manuales e intelectuales que representa Amauta. Solidaridad que no se detiene en la apropiación fraternal del dolor de los obreros de Morococha por la muerte dé algunas decenas de compañeros, si no comprende la mancomunidad en la exigencia de que la empresa minera no eluda ninguna de sus "responsabilidades" (Mariátegui, 1928, p. 94).

Mariátegui subrayó que las responsabilidades de la Cerro de Pasco eran, en primer lugar, la indemnización de las familias de las víctimas y la garantía de estabilidad laboral para aquellos mineros que quedaron ciegos a consecuencia del accidente, en cumplimiento de la ley de accidentes de trabajo. El dirigente socialista trataba de ir más allá, es decir, concertar a los intelectuales, particularmente a los ingenieros de minas y a los propios obreros en la investigación de las causas del accidente minero de Morococha. Deslindar cabalmente las responsabilidades de la empresa por omisión y negligencia, y demandar las sanciones que el caso requería. Fundamentó la participación de los mineros en el seno de la Comisión Técnica que propuso, en razón "del más elemental de sus derechos: del derecho a exigir garantías para su vida”.

En enero de 1929, Labor abordó el análisis de las condiciones de trabajo minero, reclamando la jornada de seis horas, sistemas de seguridad laboral, atención médica y sanitaria y la supresión del "régimen de enganche" (Mariátegui, 1929). Cuando el periódico cumplió su tercera entrega sobre la cuestión minera, su distribución y lectura había penetrado en Jauja y se proyectaba a los campamentos mineros.

La distribución de Labor pasó a la clandestinidad, dadas las condiciones de restricción en los campamentos mineros impuestos por la Cerro de Pasco, que prohibían todo intento de sindicalización y propaganda con la complicidad gubernamental. Se trataba de un nuevo tipo de periodismo que impulsaba el "desarrollo de ideas gérmenes" del sindicalismo clasista y del socialismo revolucionario, que aspiraba a convertirse en prensa de los trabajadores. Venía cooptando un significativo número de cronistas mineros y campesinos. Algunos tuvieron que ocultar su identidad bajo un seudónimo o el anonimato. Uno de ellos bajo el seudónimo de "El Informador", publicó en Labor. Mariátegui, desde sus páginas (1929), criticó cierta indiferencia de los trabajadores de Lima y $\mathrm{Ca}$ llao con respecto a la situación de "sus hermanos los obreros de las minas", porque siendo ellos destacamentos de la vanguardia del proletariado nacional, eran los llamados a cumplir con sus tareas de solidaridad clasista. Además, argumentaba que ellos mismos, en sus próximas o futuras jornadas de lucha, podrían recibir el aliento y el sostén moral y político que 
en ese momento demandaban, intuitivamente, los mineros.

\section{Los socialistas en Morococha: el Comité Central de Reclamos}

Mariátegui y los socialistas tenían que recurrir a la prensa, a la correspondencia y al contacto personal con los mineros, para compenetrarse con sus problemas, vibrar, acompañar y dirigir las luchas por sus reivindicaciones. Desde Lima, al igual que Martínez de la Torre, se carteaba con los mineros Adrián Sovero, Gamaniel Blanco y Héctor A. Herrera. Dicha correspondencia era clandestina. Solían llevarla y traerla Abelardo Solís y otros compañeros del núcleo de Jauja. Excepcionalmente se recurrió al servicio de correos, con las debidas precauciones de cambio de nombres y direcciones.

La primera tarea que se impusieron fue la gestación del sindicato, el cual debería ser explicado cabalmente en el seno de los mineros, tanto en sus virtudes como vehículo de lucha reivindicativa, como en sus limitaciones históricas y políticas, como organismo de clase. $\mathrm{Y}$ esta tarea era en extremo complicada por su carácter secreto, dadas las medidas represivas de la empresa y el gobierno de Leguía. Certero fue el juicio de Mariátegui sobre la situación de los mineros, la necesidad, la posibilidad y las perspectivas de su organización sindical:

Si los trabajadores estuvieran en condiciones de usar su derecho a asociarse, a organizarse, ya habrían encontrado la vía de sus reivindicaciones y una reglamentación estaría en marcha. Pero a la ignorancia de la mayor parte se une la autoridad despótica que sobre todos sus actos tiene la empresa americana, omnipotente en la región mi- nera. Cualquier tentativa de organización sería considerada como un acto de rebelión inconcebible.

Sin embargo, mientras una organización, por rudimentaria y elemental que sea, no exista, los trabajadores de las minas no conseguirán hacerse respetar por la empresa. Esta es la cuestión que los más conscientes de entre ellos tiene delante (Mariátegui, 1929).

En Morococha, el núcleo de vanguardia integrado por Adrián Sovero, J. Castillo Matos y Gamaniel Blanco, constituyó una organización intermedia para fines de desarrollo de la cultura popular en el seno del proletariado minero, la cual, a menos de cumplir un mes de fundada, selló sus vínculos con Labor. En carta fechada en Morococha, el 9 de febrero de 1929, el presidente Sovero y el secretario general Castillo Matos le escriben a Martínez de la Torre que, por acuerdo de asamblea, se le ha designado como su representante en la ciudad capital (Martínez de la Torre, 1949, p. 5).

La Sociedad Pro-Cultura Popular de Morococha impulsó los lineamientos de la autoeducación obrera, adaptados por Mariátegui a las condiciones y exigencias del trabajo en el frente minero-ferroviario-campesino. La literatura con que fue surtida esta institución cultural provenía, principalmente, de las ciudades de Jauja y Lima. El núcleo político jaujino se encargaba de la distribución de materiales de lectura y propaganda regional, capitalina (Editorial Amauta) y extranjera (pedidas a Eudocio Ravines de la célula de París, quien remitía las publicaciones de la Internacional de Trabajadores de la Enseñanza). Los pedidos a Santiago de Chile, sugeridos por Mariátegui, eran de publicaciones de la Confederación Sindical Latinoamericana (en adelante, CSLA) y 
el Secretariado Sud Americano (en adelante, SSA) de la IC. ${ }^{9}$

Mariátegui estimuló la autonomía regional en materia de distribución de literatura política. Entendía que era una actividad económica que coadyuvaría al autosostenimiento de cada regional obrera y socialista. Cabe señalar que el sedimento ideológico cultural de los adherentes a esta institución procedía, en el mejor de los casos, de la literatura liberal, libertaria y socialista (Arroyo Posadas, 1980, pp. 73-74).

A casi ocho meses de fundada la Sociedad Pro-Cultura Popular de Morococha, se marcó un nuevo hito del desarrollo político sindical del proletariado minero, al erigirse sus líderes en promotores de la defensa clasista de sus intereses, enraizando sus planteamientos en sus bases. Durante la realización de un multitudinario evento gremial se eligió a los miembros de dicha sociedad para que se encargasen de transmitir sus acuerdos al gerente de la Cerro de Pasco Corporation:

Los empleados y obreros de (...) Morococha (...), del que usted es su digno gerente general, reunidos en asamblea extraordinaria en el local del Club Movilizables nú-

9. "Convendría que el Círculo Obrero o el grupo organizador de la Federación Regional Obrera del Centro, se dirija a El Trabajador Latino-Americano, calle 9 de Abril 1653 esquina Gaboto, Montevideo, solicitándoles el envío regular de esta revista en la cantidad que se calcule necesaria. Es el órgano de la Confederación Sindical Latino-Americana, que debe haber quedado definitivamente constituida en el gran congreso sindical que acaba de celebrarse en Montevideo, y en el cual han estado representados más de 800.000 obreros organizados de la América Latina”. J. C.

Mariátegui a Moisés Arroyo Posadas. Lima, 5 de junio de 1929. Recuperado de http://archivo.mariategui.org/ uploads/r/archivo-jose-carlos-mariategui/7/0/a/70a973c3 $70867 \mathrm{dfbce} 2 \mathrm{a} 5 \mathrm{c} 659428 \mathrm{~d} 2 \mathrm{e} 9387 \mathrm{dc} 89 \mathrm{cbe} 7 \mathrm{~d} 164 \mathrm{~d} 744 \mathrm{cca} 04$ 31085948/C-1929-6-5.pdf mero 1 de Auxilios Mutuos, hoy, diez de octubre de mil novecientos veintinueve, a horas 10 p. m., y en vista de la poca atención prestada por el señor superintendente Mr. Mac Hardy, a los reclamos que, por escrito, hicieran cincuenta de nuestros compañeros, solicitando pasajes y facilidades para su movilización, por motivo de rebaja de sueldos y despedida intempestiva de sus trabajos, sin cláusula de ninguna clase, acordamos en forma unánime elevar ante su superior despacho, este Pliego de Reclamos (...) (Martínez de la Torre, 1949, p. 9).

Este acto marcó el tránsito del viejo mutualismo al sindicalismo clasista, del cual fueron síntomas inequívocos la realización de una asamblea laboral unitaria. El eje del orden del día giró en torno a la defensa de los derechos $\mathrm{y}$ reivindicaciones de empleados y mineros frente a la empresa, la formulación de un pliego de reclamos y la elección de un consejo de representantes denominado Comité Central de Reclamos: Adrián Sovero, Gamaniel Blanco, Alejandro Loli, Ramón B. Ascurra, Enrique Saravia, A. Sarabia y Alejandro Lora. Se acordó la política de negociaciones y acción huelguística. De la tradición mutualista se conservó la costumbre de apelación cortesana y patriarcal frente a las autoridades estatales y a la propia gerencia. El SSA de la IC exageró y exacerbó el aspecto formal de esta tradición cultural y política de artesanos y campesinos, que no constreñía en nada la voluntad, la capacidad y el heroísmo en la lucha de estos sectores sociales, ya que la mayoría de las veces ha hecho de preámbulo de la violencia de las masas, frente a sus adversarios de clase.

La estrategia y táctica del sindicalismo clasista del Comité Central de Reclamos de Morococha fue correcta por unitaria y justa. Les asistía la razón al demandar: la separación de Mac 
Hardy, jefe del departamento de la Cerro de Pasco en Morococha; la abolición del sistema de contratas; la garantía de estabilidad salarial y laboral; el reconocimiento del tiempo de trabajo y los derechos que confería la legislación; la aplicación y respeto de la jornada de ocho horas; el pago de horas extras y días extraordinarios de labor; el mejoramiento del servicio hospitalario y de las condiciones higiénicas y de seguridad de las viviendas de los mineros y empleados del campamento. Este hecho, ligado a la reciente reelección de Augusto B. Leguía, le confería ventaja y oportunidad especial frente a la empresa. Contaban con la necesaria flexibilidad que debía mostrar Leguía según la tradición política en el país andino, frente a las demandas populares en la coyuntura política poselectoral. La acción del Comité Central de Reclamos fue también oportuna, porque Mac Hardy polarizó a los trabajadores contra la empresa en tiempos de crisis.

El Comité Central de Reclamos puso énfasis en la violación, por parte de la empresa, de la legislación laboral, a manera de poner en evidencia que el Estado no se hacía respetar, más aún, que era cómplice de connivencia con la compañía, punto sobre el que Mariátegui insistía sutilmente, número a número, desde las páginas de Labor y Amauta.

Al día siguiente de decretada la huelga, Augusto de Romaña, prefecto del Departamento de Junín, dirigió un oficio de respuesta al Comité Central de Reclamos, dándose por enterado del conflicto y argumentando que la suspensión de labores, al no acatar las disposiciones de la Ley sobre Reglamentación de Huelgas, estaba catalogada como motín, por lo cual los emplazaba a retornar al trabajo. Además, como al día siguiente, el 12 de octubre de 1929, el residente Leguía inauguraría un período de gobierno, ofrecía, a cambio, mediar en el conflicto y obtener de la empresa una respuesta en veinticuatro horas (Martínez de la Torre, 1949, pp. 6-7).

A las pocas horas de recibido el comunicado de Romaña, el Comité le respondió con habilidad. Mientras que por un lado, manifestaba que, por unanimidad de votos y en homenaje al nuevo período presidencial de Leguía reanudarían sus labores al día siguiente, por el otro le pedía su suspensión a partir de las 3 p.m., bajo el pretexto de la celebración. Se trataba de la justificación de una acción de fuerza, de una huelga parcial, como se encarga de explicitarlo la misma carta cuando dice:

Lo único que ruega la colectividad en paro general es que los de la guardia de noche manifiestan que esperarán primeramente la respuesta definitiva al pliego de reclamaciones que indudablemente satisfacerá nuestros anhelos de justo reclamo, para poder reanudar sus tareas de costumbre, porque de lo contrario se teme que ellos no puedan volver a sus trabajos (Martínez de la Torre, 1949, p. 7).

La empresa recurrió a las autoridades gubernamentales, las cuales se encontraban en una situación política que hacía difícil tal tipo de mediación o validación de los puntos centrales del pliego de reclamos. Finalmente, la empresa impulsó la aplicación de medidas dilatorias y provocadoras en el sentido de tratar de enfrentar a los mineros con los funcionarios gubernamentales.

Harold Kingsmill, gerente general de la Cerro de Pasco, en su respuesta al pliego de reclamo de los mineros, afirmó que los salarios no se podían aumentar por el descenso de los precios de la plata, no compensados por el alza 
del cobre; además porque los salarios de Morococha eran los más altos de la región, considerando un pago adicional por concepto de labor en suelos húmedos. Este escrito también defendía a Mac Hardy, aunque insinuó que se daría un mejor trato por parte del staff de la empresa para con los trabajadores. Sostuvo que la mercantil vendería las prendas de trabajo a precio de costo y que el sobreprecio fuese de responsabilidad del Estado porque éste cargaba tributariamente a los productos importados y que en todo caso los mineros deberían pedirla exoneración de estos impuestos. Kinsgsmill cedió en el punto referente al cumplimiento de la jornada de ocho horas; el problema de los 50 despidos lo obvió y trocó con la oferta de contrata de 60 maquinistas expertos y ayudantes; ofreció resolver los pedidos de carburo y mejoramiento de vivienda. Por último, fue intransigente en la defensa del sistema de enganche, en el no pago de horas extras y optó por la consulta al Directorio de Nueva York sobre el pago de la gratificación anual y la cuestión de horas locales de los turnos de trabajo. Difirió la contrata de un médico peruano para la atención en el hospital de la empresa a una conversación ulterior y acuerdo entre Mac Hardy y el Comité Central de Reclamos (Martínez de la Torre, 1949, pp. 15-17).

Ante esta situación, los mineros respondieron el 14 de octubre, demandando la reconsideración de su pliego de reclamos. Intuían que una respuesta rápida, fundamentada y precisa, le iría dando legitimidad a la acción huelguística, cooptando la simpatía y solidaridad de los trabajadores peruanos. Combinar la negociación con las acciones de fuerza de carácter general y parcial, le depararía a corto plazo algunas satisfacciones, además de ganar experiencia para futuras luchas y mayores conquistas.
El oficio de defensa del pliego de reclamos, puso el acento: en la restitución a sus labores de los 50 despedidos; para futuros y análogos casos demandó se les notificase a los afectados con quince días de anticipación o se les pagase de inmediato el monto salarial de los mismos si la despedida fuese de tipo intempestivo, según y conforme lo prescribía la Ley del Trabajo; que los implementos de labor o faena les fueran proporcionados gratuitamente; que se les entregara a cada minero para el trabajo de socavón 12 onzas de carburo. En otros puntos presionaron con mayor insistencia, como es el caso de los aumentos salariales, los cuales plantearon que fuesen del 5 al 10 por 100, según las alzas del cobre. Cedieron parcialmente en el asunto del enganche al sostener que entrasen en vigencia algunas prescripciones sobre salarios e ingresos. En la defensa de la gratificación anual solicitaron que fuera del 8 por 100 sobre el salario, apoyándose en el precedente de 1917-1918, exigiendo que rigiera para todos los trabajadores de la Cerro de Pasco, con la clara intención de ganar nuevas adhesiones. En esta dirección, el núcleo de Jauja trabajaba en los otros campamentos mineros, distribuyéndoles un volante agitador y propagandístico en defensa de los mineros de Morococha.

Ese mismo día de la entrega del oficio, a las 4 p.m., en el local del Concejo Distrital de Morococha, se llegó a un acuerdo entre la empresa norteamericana representada por su gerente general, Harold Kingsmill, el superintendente de Morococha, Mac Hardy, los dirigentes del Comité Central de Reclamos y por parte de las autoridades gubernamentales, Romaña, prefecto de Junín. Fueron satisfactorios los acuerdos sobre: estabilidad laboral, turnos, jornadas y condiciones de trabajo, vivienda y sanidad. Quedaron pendientes las demandas de aumento salarial y gratificación anual que 
la empresa, previa consulta con el directorio de Nueva York, respondería en un plazo no mayor a quince días (Martínez de la Torre, 1949, pp. 17-18).

Se trataba de una victoria laboral que trascendía los estrechos marcos del campamento de Morococha, que hacían de éste ejemplo y vanguardia del proletariado minero peruano en la lucha por sus reivindicaciones particulares y generales. El entusiasmo reinante en Morococha tendió a fortalecer los vínculos entre mineros y empleados, a avanzar en su proceso de sindicalización y politización. Se orientaron por la táctica del sindicalismo clasista de luchar con límite, sin sobreestimar sus fuerzas. Táctica congruente con la consideración estratégica de que una huelga es sólo una batalla. Se deslindaron del sindicalismo rojo losovskiano de asumir la huelga como insurreccional, intransigente, sin límite, heroica y en aras de los soviets mineros.

Este estilo huelguístico fue sugerido y discutido por Mariátegui y los integrantes del Comité Central de Reclamos de Morococha, siendo respaldado por los trabajadores de dicho campamento. El balance de su propia experiencia les permitió elevarse de la acción intuitiva a la conciencia y adhesión a la línea sindical clasista, aproximándose en mayor grado a la organización socialista de Mariátegui.

La acción huelguística de Morococha puso en evidencia el contraste de líneas sindicales en el seno del socialismo revolucionario, liderado por Mariátegui y de la IC en América Latina. Veamos, en primer lugar, la propia valoración y reconocimiento de las limitaciones de la vanguardia minera, aparecida en el manifiesto al proletariado de Morococha: "Nuestro gran triunfo moral y material”.
El triunfo moral y material, que en justa lid se ha conseguido, sin apartarnos del camino legal, no son triunfos únicamente para esta sección obrera, sino para todas las dependencias de la referida empresa, pues nuestros respectivos pliegos de reclamaciones comprenden a todos los camaradas en general, sin egoísmos mezquinos ni cobardes.

E1 fondo moral del movimiento huelguista de los días 10 al 14 del presente, ha señalado una etapa sin parangón en los anales obreros de Morococha, si llegamos a juzgar con criterio la nobleza y optimismo de las gestiones, desde su iniciación hasta el final; en cuyas fechas, de gran trascendencia obrerista, se han sentado las bases de una justísima reclamación, encuadradas en el campo del derecho y el respeto a las propiedades del capitalista. Nuestro movimiento no ha sido de aquellos que se asemejan a motines sin control (Martínez de la Torre, 1949, pp. 8-9).

Ese apego al legalismo fue más producto de la fraseología liberal y del sindicalismo socialista y reformista, que de su propia experiencia de huelga. La propaganda de Amauta y especialmente de Labor, incidió en el respaldo legal de parte de sus reivindicaciones frente a la Cerro de Pasco. Sus voceros utilizaron el conflicto laboral como medio para polarizar la opinión popular contra las violaciones de las normas más elementales de la vida y el trabajo, así corno para poner en evidencia al estado semicolonial, es decir, la complicidad de intereses oligárquicos e imperialistas. La otra limitación de la vanguardia minera fue su percepción de que sus problemas laborales se debían a la mala gestión de Mac Hardy. Pero estas ideas erróneas, más no oportunistas, serían decantadas a la luz de la reflexión sobre su propia experiencia de lucha. Lo que habría que revelar era la unidad de cohesión en la lucha, la flexibilidad 
en las negociaciones para ceder selectivamente en algunos puntos y ser intransigente en otros.

\section{Cierre de palabras: Balance y cambio de rumbo}

Nuestro aporte es producto de una reinterpretación de las fuentes documentales, apoyado en el testimonio de Jorge del Prado (2010) y dos entrevistas. La propuesta fue la de reconstituir la existencia de un proyecto estratégico diseñado y dirigido por Mariátegui para la Sierra Central. En función de ello, se subrayó la existencia de redes socialistas y sindicales interétnicas, discriminándolas de los contactos o vínculos ocasionales. Las redes de Mariátegui fueron cultivadas y reafirmadas como política y culturalmente significativas. Su estudio permitió dotar de visibilidad al espacio estratégico generado por los socialistas liderados por el director de Labor. Su traducción regional delimitó el papel asignado a algunas localidades: Morococha, Jauja, La Oroya, Muquiyauyo, entre otras. Su articulación deja abierta una interrogante étnica acerca del modo huanca de espacialización para el cual, lo discontinuo y disperso es el preámbulo de su base de unidad y reconcentración, contrariando la visión criollo-occidental euclidiana sobre la espacialidad continua, serial y unitaria. Las categorías en quechua que significan a esta aparente polaridad son taqe y cheqesqa, facilitadas por la migración estacional y el desplazamiento de cuadros vía el tejido ferroviario.

Mariátegui y el núcleo socialista, hostigados y reprimidos por el gobierno, avanzaron hasta donde les permitieron sus fuerzas en la construcción de su inconcluso espacio estratégico regional de fuerte contenido comunal y pro- letariado mixto. Otro tiempo y lógica político-sindical se venía cribando.

Entre finales de 1929 y 1930, la crisis internacional golpeó con dureza al Perú. Fueron cortados los empréstitos estadounidenses al gobierno de Leguía iniciando su tercer mandato, lo cual agravó su desgaste y descrédito por acción de las fuerzas de oposición política, el malestar popular y la oleada beligerante de la clase obrera y del campesinado. La contracción del mercado internacional y el desplome de los precios de los productos agro mineros de exportación, incidió en un mayor autoritarismo y represión gubernamental. Mariátegui, con la salud minada y hostigado por la policía política, padeció su detención y la de muchos cuadros socialistas, la prohibición a la edición de Labor y una nueva amenaza a Amauta. Haber enfilado su crítica y acción contra la $\mathrm{Ce}$ rro de Pasco le implicó un costo muy alto que adelantó el agravamiento de su salud, tras su detención y huelga de hambre. No obstante, su extrema debilidad física, su lucidez y entusiasmo revolucionario no decayó y en memorable carta a Moisés Arroyo Posada, el 16 de noviembre de 1929, comunicó su balance de la lucha de los mineros de Morococha frente al gobierno central:

Excelente y oportuno el volante solicitando la solidaridad de los mineros de Cerro de Pasco, Oroya, etc., para sus compañeros de Morococha. Ha estado en Lima el Comité de Morococha, pero no ha conseguido el éxito que esperaba de sus gestiones. La empresa se niega a conceder el aumento. Y el gobierno, por supuesto, no la ampara. Lo que interesa, ante todo, es que los obreros aprovechen la experiencia de sus movimientos, consoliden y desarrollen su organización, obtengan la formación en la Oroya, Cerro de Pasco y demás centros mineros del 
Departamento de secciones del Sindicato, etc. No deben caer, por ningún motivo, en la trampa de una provocación. A cualquiera reacción desatinada, seguiría una represión violenta. Eso es probablemente lo que desea la empresa. La lucha por el aumento quedaría así sólo aplazada para volver a ella en momento más favorable y con acrecentadas fuerzas. Conviene que converse usted sobre esto con el compañero Solís y que escriba a Morococha (Arroyo Posadas, 1980, pp. 73-74).

Una semana más tarde, en otra carta dirigida a Samuel Glusberg, su amigo en Buenos Aires, brindó más detalles de esa lucha minera que lo involucraba ante los ojos del poder:

Mi casa es designada como el centro de la conspiración. Se me atribuye especial participación en la agitación de los mineros de Morococha, que en reciente huelga, que ha alarmado mucho a la empresa norteamericana, han obtenido el triunfo de varias de sus reivindicaciones, entre otras las de su derecho a sindicarse. El gobierno acaba de obligar a los obreros a renunciar al aumento que gestionaban. Y se teme que nosotros defendamos e incitemos a los obreros a la resistencia. ${ }^{10}$

Mariátegui adhirió a la tesis de la lucha prolongada, multilateral y ascendente, es decir, la oponía a la concepción del sindicalismo faccional acerca de la lucha inmediata y final. A las acciones huelguísticas que no contaban con la retaguardia estratégica de las acciones solidarias de otros destacamentos obreros, había que oponerle la necesidad de combinar el repliegue táctico y la ofensiva sindical. Mariátegui consideraba que al proletariado minero le tocaba una fase de crítica y preparación de fuerzas, en

10. Mariátegui a César Alfredo Miró Quesada. Lima, 22 de noviembre de 1929 (1994, pp. 2048-2049).

144 el sentido de ampliar y elevar el nivel de sindicalización y politización, cuyos objetivos a corto plazo presuponían la formación de una federación vertical que aglutinase al proletariado minero y de una federación de tipo horizontal que cohesionase a todos los destacamentos laborales de la ciudad, el campo y las minas en el centro del país. En la carta arriba citada, Mariátegui recomendaba a Arroyo Posada:

Dígale a Solís que el acta de fundación de la Federación de Trabajadores del Centro, adherente e integrante principal de la federación, en la que tienen cabida sindicatos de oficios varios y comunidades y sindicatos agrícolas. La organización por industria es indispensable. El sindicato de mineros y fundidores del Centro será además el punto de partida de la Federación de Mineros de Perú; se gestionará, pues, del Ministerio de Fomento el reconocimiento oficial de dos organizaciones (Arroyo Posadas, 1980, p. 61).

Fue precisamente en esa coyuntura que reapareció la confrontación de líneas sindicales en el seno del movimiento socialista revolucionario. Por un lado, el sindicalismo clasista sostenido por Mariátegui y, por el otro, el sindicalismo rojo, representado por Ricardo Martínez de la Torre, Esteban Pavletich y Eudocio Ravines, respaldados por el SSA de la IC y el Comité Ejecutivo de la CSLA. Tal controversia tuvo un antecedente explícito a fines de 1928 a raíz de la valoración de las jornadas huelguísticas de 1919 en Lima y Callao:

Los juicios del autor sobre el confusionismo y desorientación de que fatalmente se resentía la acción obrera, en esa jornada y sus preliminares, me parecen demasiado sumarios. Martínez de la Torre no tiene a veces en cuenta el tono incipiente, balbuceante, instintivo de la acción clasista de 
1919. Después de su victoriosa lucha por la jornada de ocho horas, es esa la primera gran agitación del proletariado de Lima y el Callao, de carácter clasista (Mariátegui, 1987, p. 182).

Martínez de la Torre, en carta del 10 de noviembre de 1929 dirigida a Héctor A. Herrera, expresó implícitamente su desacuerdo con Mariátegui. Afirmó que los mineros estaban expuestos a "graves vacilaciones y errores" y clamó que era el momento para que el partido elevase su "mentalidad clasista" porque todos sus dirigentes son "desorientados, ignorantes en cuestiones de organización” (Martínez de la Torre, 1949 , p. 22). Lo único positivo era que mantenían vínculos con el "grupo de Lima" y que eran receptivos a "indicaciones y sugerencias”. En el fondo compartía la concepción de la "masa rebaño", cara a la visión cominternista del "tercer periodo".

Fue el propio Martínez de la Torre quien reprodujo un informe al SSA de la IC. Su contenido resumió la concepción faccional del sindicalismo rojo, sus afanes inmediatos, su intransigencia aventurera. Le pareció una desviación encontrar, como lo hizo Mariátegui, un saldo positivo de la experiencia de la lucha minera de Morococha, ya que solo percibía conciliación, deslealtad e injerencia estatal por todas partes:

Leguía interviene activamente, pues, en el movimiento huelguista, corrompe a sus jefes, los sienta junto a los representantes de la Corporation y del delegado gubernativo, les hace renunciar a las exigencias relativas al aumento de salario y, luego, presiona sobre la empresa para que ceda algunas pequeñas migajas. Resultado: la huelga termina, el movimiento ha sido nuevamente quebrado; los dirigentes de los huelguistas han traicio- nado directamente a las masas; han admitido no insistir en lo del aumento salarial, sometiéndose a la buena voluntad que, en el futuro, mostrará el presidente Leguía. Han entregado a las masas y han destroncado la huelga. La "solución" del conflicto de Morococha tiene bases muy débiles e inestables; todas las condiciones que lo generaron quedan en pie, y no cuesta trabajo prever nuevos movimientos de los obreros mineros (SSA-IC, 1929, p. 5).

El deceso de Mariátegui facilitó la intervención de la CSLA y del SSA de la IC en la nueva orientación partidista y sindical. La vanguardia minera fue descabezada por el propio faccionalismo rojo. Pavletich, en su testimonio, se enorgulleció de las siguientes prácticas en La Oroya: "al llegar tomamos de rehenes al superintendente de la Cerro de Pasco Copper Co. y al superintendente de la Sociedad Agrícola Ganadera de Junín. Era la primera vez en el Perú que se hacían guardias proletarias" (Melgar Bao, 1974, p. 23). Días más tarde, "los rojos" sucumbieron heroicamente defendiendo sus "soviets mineros" en La Oroya y Malpaso (Flores Galindo, 1974,pp. 101-109).

En cuanto a los cuadros socialistas, tras la muerte de Mariátegui el 30 de abril de 1930, unos se reposicionaron como comunistas partidarios de las tesis y métodos del cominternismo del "tercer periodo"; otros fueron purgados o se retiraron del Partido. El sindicalismo rojo se impuso en los años de 1930 y 1931. En el frente minero se sintieron con sus acciones, muy cerca del asalto al cielo.

El sindicalismo rojo presumió haber confrontado y superado las posiciones del anarcosindicalismo, del sindicalismo revolucionario y del sindicalismo clasista. Fetichizó la huelga como medio de lucha desde una óptica voluntarista y 
aventurera. Toda huelga de cierta envergadura debía de ser llevada hasta sus últimas consecuencias convirtiéndose en "escuela de guerra" y dar el salto a volverse la guerra revolucionaria. La huelga general y la insurrección armada eran las dos fases obligadas de un general y único proceso revolucionario (Losovsky, 1930a).

El sindicalismo rojo sobrestimó la influencia moral que podía ejercer la acción huelguística sobre las clases trabajadoras. La huelga roja fue considerada como un cúmulo de acciones de masas: tomas, movilizaciones, mítines, sabotajes, proclamas, volantes, etc., que deberían desarrollarse de manera intensa, intermitente $\mathrm{y}$ ascendente. Este estilo del voluntarismo pequeño burgués terminó desgastando a las bases y a sus organizaciones sindicales. Eudocio Ravines dejó testimonio elocuente de la óptica prevaleciente en la cúpula de la Comintern:

La espectacular insurgencia de La Oroya llenó de pavor al gobierno, electrizó a los trabajadores y causó verdadero asombro en Moscú y una magna impresión en el Buró Sudamericano. -Ningún partido comunista emprendió y cumplió, al nacer, tal hazaña-, repetía sobreexcitado Guralsky, atribuyendo al hecho una magnitud sobresaliente y proyecciones insospechables. Y su apreciación no solo fue ratificada sino exaltada por el Comintern, que calificó la acción de los mineros peruanos como "hecho ejemplar en los anales de la Revolución proletaria mundial". Para mí lo admirable fue que obreros tan inexpertos interpretasen con tal intuición las enseñanzas (Ravines, 1952, pp. 180).

El legado de Mariátegui en tiempos de la gran crisis de 1929-1933 fue devaluado, inclinán- dose del lado del sindicalismo de hierro y combate sin límite.

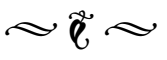




\section{Referencias Bibliográficas:}

Arroyo Posadas, M. (1980). La correspondencia de José Carlos Mariátegui a Jauja. Allpanchis, XIV(16), 61-74.

Barcelli, A. (1971). Historia del sindicalismo peruano. Lima: Hatunruna.

Barrientos, L. F. (1958). Los tres sindicalismos: sindicalismo proletario, sindicalismo patronal, sindicalismo politico. Lima: Ediciones Continente.

Del Prado, J. (2010). Los mineros de la Sierra Central y la masacre de Malpaso. En Jorge del Prado y los mineros de la Sierra Central. Testimonio sobre la masacre de Malpaso (pp. 27-102). Lima: Fondo Editorial del Congreso del Perú.

Falcón, C. (1927). El conflicto minero [parte I y II]. Amauta (5 y 6), 3-4; $27-28$.

Ferry, J.-M. (1992). El nuevo espacio público. Barcelona: Gedisa.

Flores Galindo, A. (1974). Los mineros de la Cerro de Pasco. 1900-1930. Lima: PUCP.

Kapsoli, W. (1972). Los movimientos campesinos en Cerro de Pasco. Lima: Universidad Nacional Mayor de San Marcos.

Kapsoli, W. (1980). El pensamiento de la Asociación Pro Indigena. Lima: Centro de Estudios Rurales Andinos Bartolomé de las Casas.

Kruijt , D. y Vellinga, M. (1980). Las huelgas en la Cerro de Pasco Corporation (1902-1974): Los factores internos. Revista Mexicana de Sociología, 42(4), 1497-1588.

Lefebvre, H. (2013). La producción del espacio. Madrid: Capitán Swing.

Lévano, C. (28 de noviembre de 2016). Entrevista a Julio Portocarrero. "De los que sobreviven", diálogo con Julio Portocarrero. Recuperado de Fundación César Lévano: http://fundacionlevano.org/2016/11/28/ de-los-que-sobreviven-dialogo-con-julio-portocarrero/

Losovsky, A. (1930a). El Movimiento Sindical Latinoamericano, sus virtudes y sus defectos. Montevideo: Ediciones del Comité Pro Confederación Sindical Latinoamericana.

Lozovski, A. (1930b). Diez años de vida de la Internacional Sindical Roja. Montevideo: Confederación Sindical Latino Americana.

Mariátegui, J. C. (1928). Las responsabilidades de la catástrofe de Morococha. Amauta (19), 94-95.

Mariátegui, J. C. (1929). Las condiciones del trabajo en las minas. Labor (5), 1.

Mariátegui,J. C. (1957). Siete ensayos de interpretación de la realidad peruana. Lima: Empresa Editora Amauta. 
Mariátegui, J. C. (1987). Obras completas, vol. 13. Ideología y política. Lima: Empresa Editora Amauta.

Mariátegui, J. C. (1994). Mariátegui total, vol. 1. Lima: Empresa Editora Amauta.

Marof, T. (1929). Bolivia y la nacionalización de las minas. Amauta(21), 84-93.

Martínez de la Torre, R. (1949). Apuntes para una interpretación marxista de la bistoria social del Perú, vol. IV. Lima: Empresa Editorial Peruana.

Mazzi, V. (2017). Impacto de Amauta en la prensa minera de Morococha (1926-1930). Utopia y Praxis Latinoamericana, 22(77), 89-99.

Mejía, R. J. (1971). Informe de nuestra visita a la comunidad de Laraos. Lima: PUCP.

Melgar Bao, R. (1974). Mariátegui, el Partido y el Primer Congreso Minero [entrevista a Esteban Pavletich, realizada el 8 de abril de 1972]. Cuadernos Mineros(2), 20-26.

Melgar Bao, R. (1988). El Movimiento Obrero Latinoamericano. Historia de una clase subalterna. Madrid: Alianza.

Melgar Bao, R. (2016). La prensa militante en América Latina y la Internacional Comunista. México: INAH.

Melgar Bao, R. y Montanaro, M. (2010). Victor Raúl Haya de la Torre a Carlos Pellicer. Cartas Indoamericanas. México: Taller Abierto.

Pécaut, D. (1973). Política y sindicalismo en Colombia. Bogotá: La Carreta.

Portocarrero, J. (1987). Sindicalismo peruano. Primera etapa, 1911-1930. Lima: Gráfica Labor.

Pulgar Vidal, J. (1967). Geografía del Perú: las ocho regiones naturales del Perú. Lima: Ansonia.

Ravines, E. (1952). La gran estafa. México: Libros y Revistas, S. A.

Sánchez Ortiz, G. (1987). La prensa obrera 1900-1930 (análisis de El obrero Textil). Lima: Barricada.

SSA-IC.(1 de diciembre de 1929).La nueva ola de represión en el Perú. La Correspondencia Sudamericana(22), 4-6.

Sulmont, D. (1980). Historia del movimiento obrero minero metalúrgico. Lima: Asociación Trabajo y Cultura.

Vitale, L. (1986). A 100 años de Chicago. El movimiento obrero latinoamericano. Nueva Sociedad(83), 5465.

Zavaleta, R. (2009). El Estado en América Latina. En La autodeterminación de las masas (pp. 321-355). Bogotá: CLACSO/Siglo del Hombre Editores. 